\title{
Dermatite das fraldas, fisiopatologia e tratamento: revisão de literatura
}

\author{
Diaper dermatitis, pathogenesis and treatment: literature review
}

\author{
James da Silva Rocha Filho ${ }^{1}$, Carlos Gilvan Nunes de Carvalho ${ }^{2}$
}

Rocha Filho JS, Carvalho CGN. Dermatite das fraldas, fisiopatologia e tratamento: revisão de literatura/ Diaper dermatitis, pathogenesis and treatment: literature review. Rev Med (São Paulo). 2017 jul.-set.;96(3):183-6.

RESUMO: Introdução: A dermatite de Jacquet (DJ) é uma dermatite de contato por irritante primário de caráter multifatorial, que possui pico de incidência entre o sétimo e o décimo segundo mês de vida, sendo que $50 \%$ dos infantes serão acometidos por tal enfermidade em algum grau. Portanto, a DJ é a afecção cutânea mais frequente na primeira infância. Clinicamente a enfermidade caracteriza-se por pápulas salientes e firmes, de coloração vermelho-escura ou violácea, que sucedem uma fase vésicoerosivo-ulcerativa. Objetivo: O estudo possui como objetivo prover informações acerca de um subtipo morfológico raro de dermatite irritativa das fraldas na prática clínica, a DJ. Dessa forma, espera-se contribuir para facilitar o diagnóstico e condutas terapêuticas tanto por profissionais quanto por acadêmicos. Metodologia: Foi feito uma revisão nas principais bases de dados buscando artigos que contemplassem o assunto. Discussão: A DJ é interpretada como o resultado final de uma cascata de eventos, desencadeada inicialmente por lesões no nível do estrato córneo, induzidas por exposição a múltiplos fatores, tais como: hiperhidratação, fricção, temperatura, irritantes químicos, urina e fezes. Portanto, após o comprometimento da barreira cutânea, vários fatores adicionais do mesmo tipo potencializam essas alterações originando um ciclo vicioso vulnerável às infecções por agentes microbianos oportunistas, como Candida albicans, que é fator agravante frequente. Por isso, o desenvolvimento da dermatite da área da fralda irritativa primária possui caráter multifatorial. Conclusão: Por ser a afecção cutânea mais prevalente na primeira infância, constituindo fonte significativa de desconforto para a criança, é importante que se conheça a fisiopatologia da doença para que haja a correta prevenção e tratamento. A melhor conduta é a prevenção. Ademais, nos últimos tempos, observouse diminuição da frequência e gravidade da dermatite da área das fraldas, principalmente, devido à melhoria na qualidade do material utilizado em sua confecção, o que contribuiu sobremaneira para o avanço nos cuidados de higiene.

Descritores: Dermatite das fraldas/fisiopatologia; Fenômenos fisiológicos da pele; Terapêutica.

ABSTRACT: Introduction: Jacquet's dermatitis is an irritant contact dermatitis, which has a peak incidence between the seventh and twelfth month of life, and 50\% of infants are affected by this disease in some level. Clinically, Jacquet's dermatitis is characterized by firm papules and protruding from dark red or violet, which succeed one vesico-erosive-ulcerative stage. Objective: This study has the objective of providing information about a rare morphological subtype irritant diaper dermatitis in clinical practice, Jacquet's dermatitis. Therefore, it is expected to help facilitate the diagnosis and therapeutic management both by practitioners and academics. Methodology: This study is a literature review that addressed the issue. Discussion: The wearing of diaper leads to over hydration, increased local temperature and humidity. Constant maceration and prolonged contact with urine and stools makes the skin under the diaper more susceptible. There is often secondary infection due to Candida. Conclusion: The best thing to do to avoid Jaquet's dermatitis is prevention. Treatment is simple and depends on dermatitis type and severity. Moreover, in recent times, there was a decrease in the frequency and severity of dermatitis in the diaper area, mainly due to improvement in the quality of the material used in their manufacture, which greatly contributed to the advancement in hygiene.

Keywords: Diaper hash/physiopathology; Skin physiological phenomena; Therapeutics.

1. Graduando em Medicina pelo Centro Universitário UNINOVAFAPI. E-mail: amesrochafilho@gmail.com.

2. Médico especialista em infectologia. E-mail: gilvnunes@gmail.com.

Endereço para correspondência: James da Silva Rocha Filho. Rua Aristides Saraiva de Almeida, 960 - Bl. D, Apto 704. Teresina, Pi. CEP: 64053-300. 


\section{INTRODUÇÃO} e acordo com Fernandes et al. ${ }^{1}$ existe um
conjunto de dermatoses inflamatórias que atingem as áreas do corpo cobertas pela fralda - a região composta por períneo, região glútea, abdômen inferior e coxas.

Contudo, principalmente para fins didáticos, incluem-se nas dermatites de áreas de fraldas: I) as erupções causadas pelo contato direto com a fralda, como a dermatite irritativa primária e a dermatite de contato alérgica ao material plástico da fralda, II) as dermatites exacerbadas devido ao uso da fralda e III) aquelas que ocorrem nessa localização, mas que não estão relacionadas com o uso da fralda.

Rocha e Selores ${ }^{4}$ dividem ainda a dermatite irritativa primária em dois subtipos morfológicos menos frequentes: um mais brando conhecido por "dermatites das marés"' e um subtipo mais severo conhecido por "dermatite de Sevestre-Jacquet".

Descrita em 1905 por Jacquet, a dermatite de Jacquet é uma dermatite de contato por irritante primário de caráter multifatorial, que possui pico de incidência entre o sétimo e o décimo segundo mês de vida, sendo que $50 \%$ dos infantes serão acometidos por tal enfermidade em algum grau ${ }^{3}$. Portanto, a dermatite de Jacquet é a afecção cutânea mais frequente na primeira infância. Contudo, crianças de outras faixas etárias e adultos que usam fraldas - situações especiais que as levem à incontinência urinária e fecal - confluem para quadro clínico, complicações e ações terapêuticas semelhantes ${ }^{1-3}$.

Clinicamente a dermatite de Jacquet caracteriza-se por pápulas salientes e firmes, de coloração vermelhoescura ou violácea, que sucedem uma fase vésico-erosivoulcerativa. As ulcerações são ovais ou redondas, com fundo raso e de configuração crateriforme. Esse tipo de dermatite pode regredir com atrofia e hiperpigmentação ${ }^{3}$. Nos meninos, as úlceras podem ocorrer na glande e meato urinário, levando a desconforto e disúria, e o diagnóstico é eminentemente clínico ${ }^{3}$.

\section{OBJETIVO}

O estudo possui como objetivo prover informações acerca de um subtipo morfológico raro de dermatite irritativa das fraldas na prática clínica, a dermatite de Jacquet. Dessa forma, espera-se contribuir para facilitar o diagnóstico e condutas terapêuticas tanto por profissionais quanto por acadêmicos.

\section{METODOLOGIA}

Foi feito uma revisão nas principais bases de dados (PUBMED, SciELO e BIREME) buscando artigos que contemplassem o assunto.

\section{DISCUSSÃO}

Segundo Berg (1986, apud Fernandes et al. ${ }^{1}$ ), a dermatite da área da fralda irritativa primária é interpretada como o resultado final de uma cascata de eventos, desencadeada inicialmente por lesões no nível do estrato córneo, induzidas por exposição a múltiplos fatores, tais como: hiper-hidratação, fricção, temperatura, irritantes químicos, urina e fezes. Portanto, após o comprometimento da barreira cutânea, vários fatores adicionais do mesmo tipo potencializam essas alterações originando um ciclo vicioso vulnerável às infecções por agentes microbianos oportunistas, como Candida albicans, que é fator agravante frequente $^{1}$. Por isso, o desenvolvimento da dermatite da área da fralda irritativa primária possui caráter multifatorial.

De acordo com Fernandes et al. ${ }^{1}$, a fralda, por si só, muito raramente está implicada no desenvolvimento de dermatites de contato irritativas ou alérgicas em crianças. As fraldas descartáveis modernas possuem três camadas: uma interna que funciona como filtro, uma intermediária com capacidade de absorção de líquidos, e uma externa à prova de água. Esta última camada tem papel fundamental na impermeabilidade da fralda, porém previne a perspiração, o que aumenta a temperatura e umidade locais. Por outro lado, as fraldas modernas são mais oclusivas, sendo responsáveis pelos casos raros de dermatite de contato alérgica.

A fricção entre pele-pele e pele-fralda durante os movimentos da criança, embora não seja fator dominante, é, no mínimo, predisponente. Esse fato é apoiado pela predileção dessa dermatite pelas superfícies côncavas (genitais, região glútea, parte inferior do abdômen e área proximal das coxas) e pelo não acometimento das pregas. Por essa localização peculiar, essa forma de dermatite da área das fraldas é conhecida como em "W"4.

Com relação à hidratação, um ambiente de hiperhidratação é causado não apenas pelas fraldas, mas também pela ureia urinária e por certas situações clínicas como febre. Apesar das fraldas modernas conterem material absorvente que reduzem a umidade, o ambiente quente e úmido não foi ainda completamente eliminado. A hidratação excessiva torna a pele mais susceptível à fricção originada pela movimentação sob a fralda. Além disso, é responsável por maceração cutânea que leva, posteriormente, a alterações da função de barreira da epiderme, criando o ambiente ideal para a proliferação de micro-organismos ${ }^{1}$.

Quanto às fezes e urina, apesar da amônia liberada na degradação bacteriana da ureia urinária, não constituir a causa primária da dermatite da área das fraldas, pode atuar como fator agravante em pele previamente lesionada. A ureia é convertida por bactérias em amônia, que eleva o pH cutâneo ${ }^{1}$. Estudos recentes sugerem que a elevação do pH local aumenta a atividade das proteases e lipases fecais, que são fatores importantes na etiopatogenia da dermatite. Sabe-se ainda que a exposição prolongada da pele à urina 
aumenta a permeabilidade a substâncias irritantes. As fezes das crianças contêm quantidades importantes dessas enzimas digestivas proteolíticas e lipolíticas que, quando em contato prolongado com a superfície cutânea coberta pela fralda, causam alterações consideráveis na barreira epidérmica. Uma das situações clínicas que evidencia esse fato é a diarreia, em que o contato com as fezes é prolongado.

Já o aumento da temperatura local causado pela dificuldade que a fralda impõe de perspiração da pele subjacente, leva à vasodilatação e, consequentemente, à inflamação ${ }^{4}$.

Diante deste contexto, a pele fica a mercê de uma infecção secundária devido à lesão de suas barreiras, caracterizando a principal complicação das dermatites irritativas primárias. Logo, existe uma associação da dermatite com superinfecção por Candida albicans, Staphylococcus aureus, micro-organismos da flora cutânea e intestinal, bactérias como Bacillos faecallis, Proteus, Pseudomona e Streptococcus. A Candida albicans contamina frequentemente crianças com dermatite da área das fraldas com mais de três dias de evolução, sendo muito raramente isolada nessa região na ausência de dermatite ${ }^{1,2}$.

$\mathrm{O}$ tratamento médico da dermatite da área das fraldas irritativa primária consiste em medidas simples, aplicadas de acordo com a gravidade e o tipo de dermatite. De acordo com Zanini ${ }^{3}$, a orientação médica principal na dermatite da fralda é a preventiva, que consiste na escolha adequada da fralda, frequência de trocas, limpeza e uso de produtos de barreira (vaselina, lanolina e óxido de zinco) a fim de reduzir o contato da pele com a urina e as fezes. A higienização deve ser frequente, mas não excessiva nem agressiva (fricção), e pode ser feita com sabão de coco ou sabonetes neutros.

Para dermatite instalada de grau leve, o mais importante consiste no aumento da frequência de trocas e na utilização de fraldas superabsorventes. Devem-se evitar, também, fraldas de pano que permitem maior contato da urina e fezes com a pele e exigem medidas de eliminação de micro-organismos (lavagem com sabão e fervura). É recomendável, na limpeza da área da fralda, lavar em água corrente para melhor remoção de resíduos e uma possibilidade é o uso até três vezes ao dia de compressas frias com solução de Burow 1:30, que confere efeito calmante, antisséptico e secativo ${ }^{2}$.

Se o eritema persistir, pode-se associar corticóide tópico de baixa potência, como hidrocortisona a $1 \%$, no máximo duas vezes ao dia por dois a sete dias a fim de aliviar a inflamação. Corticóide fluorado, de potência mais elevada está contraindicado pelo risco inerente de atrofia e de estrias, além de o efeito oclusivo da fralda aumentar sua potência. Deve-se ficar atento também aos efeitos colaterais sistêmicos dessa substância, como síndrome de Cushing e hipertensão intracraniana, que têm sido relatados mesmo com os de baixa potência, pois, além da oclusão, a superfície corporal dessa área é significativa ${ }^{2-3}$.

Contudo, se a dermatite não melhora, mantendo eritema intenso e pústulas, a suspeita principal é de infecção por Candida. Nesse caso, se poderá adicionar duas vezes ao dia por sete a 15 dias creme com ação antifúngica, como cetoconazol, nistatina a $100.000 \mathrm{U} / \mathrm{g}$ ou nitrato de miconazol $1 \%$ tópico, que são eficazes e seguros. O corticóide pode ser revezado com o antifúngico, aplicando-os antes do creme barreira ${ }^{2}$.

Já infecções bacterianas são mais raras com as fraldas descartáveis do que eram com as de pano e podem ser tratadas com neomicina, gentamicina ou mupirocinatópicas a 2\%. Esta última, entretanto, não deve ser utilizada em mais de $20 \%$ da superfície corporal pelo risco de nefrotoxicidade. Frisar que os antibióticos orais podem agravar o quadro por afetar a flora intestinal ${ }^{2-4}$.

\section{CONCLUSÃO}

Por ser a afecção cutânea mais prevalente na primeira infância, constituindo fonte significativa de desconforto para a criança, é importante que se conheça a fisiopatologia da doença para que haja a correta prevenção e tratamento. A melhor conduta é a prevenção. Ademais, nos últimos tempos, observou-se diminuição da frequência e gravidade da dermatite da área das fraldas, principalmente, devido à melhoria na qualidade do material utilizado em sua confecção, o que contribuiu sobremaneira para o avanço nos cuidados de higiene.

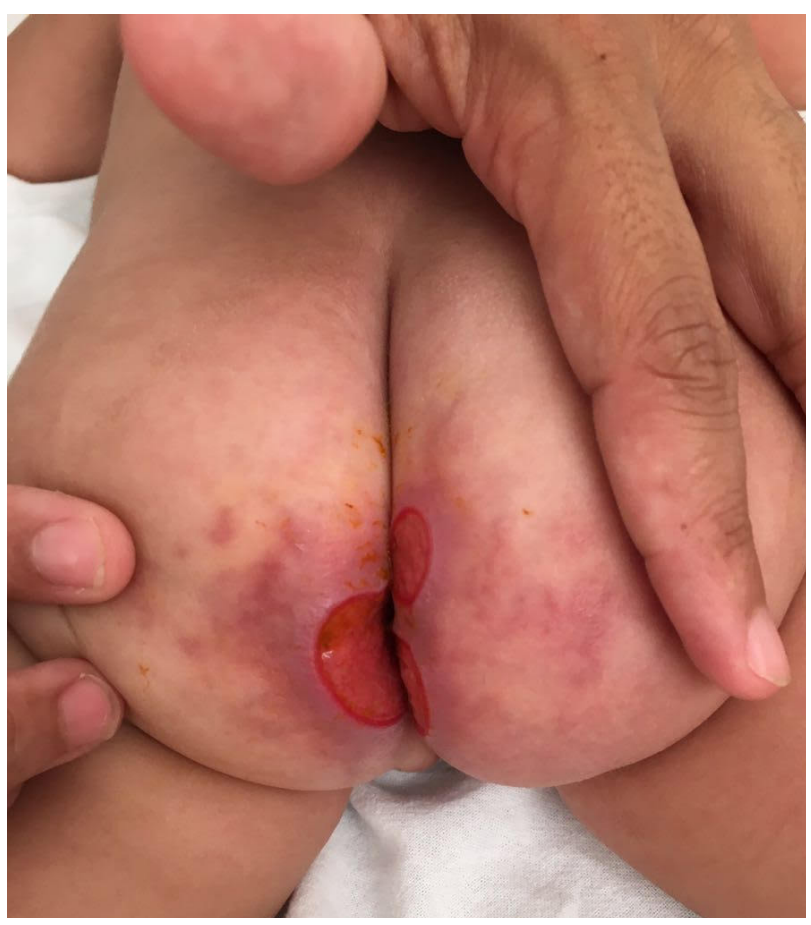

Figura 1. Paciente com dermatite das fraldas associada à infecção por Pseudomona. À imagem: extensas ulcerações cutâneas, mucosas com eritema perilesional em região perianal e teste positivo para Pseudomona. (Foto autorizada pela mãe da paciente) 
Rocha Filho JS, Carvalho CGN. Dermatite das fraldas, fisiopatologia e tratamento.

\section{REFERÊNCIAS}

1. Fernandes JD, Machado MCR, Oliveira CNP. Fisiopatologia da dermatite da área das fraldas - parte I. An Bras Dermatol. 2008;83(6):567-71. doi: 10.1590/S0365-05962008000600012.

2. Fernandes JD, Machado MCR, Oliveira CNP. Quadro clínico e tratamento da dermatite da área das fraldas - Parte II. An Bras Dermatol. 2009;84(1):47-54. doi: 10.1590/S036505962009000100007

Artigo recebido em: 26.09.2016

Artigo aceito em: 15.05.2017
3. Zanini M, Wulkan C, Paschoal LHC, Paschoal FM. Erupção pápulo-ulcerativa na região da fralda: relato de um caso de dermatite de Jacquet. An Bras Dermatol. 2003;78(3):355-9. doi: 10.1590/S0365-05962003000300012.

4. Rocha N, Selores M. Dermatite das fraldas. Nascer Crescer Rev Hosp Crianças Maria Pia. 2004;13(3):206-14. Disponível em: http://www.hmariapia.min-saude.pt/revista/vol1303/ Dermatite\%20das\%20fraldas.pdf. 